\title{
Desplazamientos y gentrificación, ¿̨una relación necesaria? Estudio cuantitativo en la ciudad de Córdoba, Argentina (1991-2010)
}

Gonzalo-Martín Rodríguez. Centro de Estudios Urbanos y Regionales (CEURCONICET), Buenos Aires, Argentina.

RESUMEN | El fenómeno de los desplazamientos de población de clase baja se asume generalmente como asunto clave al momento de evaluar el impacto de políticas públicas e iniciativas privadas orientadas a la renovación urbana y gentrificación en las áreas centrales. El presente trabajo propone una metodología cuantitativa donde, a partir de datos censales, se examina si la llegada de clases medias y altas a un sector central de la ciudad (uno de los aspectos más característicos de la gentrificación) guarda relación con el posible desplazamiento de habitantes originarios de clase baja. El caso de estudio es la ciudad de Córdoba, Argentina, entre los años 1991 y 2010. Los resultados sugieren que el desplazamiento de clases bajas es fuerte en el área central, pero estos desplazamientos no estarían necesariamente vinculados a la gentrificación.

PALABras ClaVe | gentrificación, desigualdad social, distribución espacial.

ABSTRACT | Lower class displacement is generally assumed as a major concern when evaluating the effects of gentrification and urban renewal policies in inner city areas. This work proposes a quantitative methodology based on census data and cartography to determine if moving in middle class residents (one key aspect of gentrification), has a relationship with lower class original residents' displacement. Our case of study is the city of Córdoba, Argentina, between 1991-2010. Results suggest that although displacement levels are high for the central area, they are not necessarily related to gentrification.

KEYWORDs | gentrification, social inequality, spatial distribution. 


\section{Introducción}

En la más reciente conferencia Hábitat III, realizada en Quito, representantes de todo el mundo acordaron manifestarse en favor de políticas públicas, incluida la renovación urbana, que apunten a evitar la profundización de los procesos de segregación y gentrificación, y los desplazamientos — presumiblemente inducidos por la última-, todo ello en el marco más amplio de un llamado a garantizar el Derecho a la Ciudad (Naciones Unidas, onu, 2016). De esta manera, Naciones Unidas introduce por primera vez la gentrificación y los desplazamientos como problemas que los gobiernos locales y demás actores están llamados a atender.

Entre los desafíos que se plantea a los investigadores, está el producir conocimiento orientado a la medición y monitoreo de los desplazamientos, y la determinación de su posible vínculo con políticas de renovación urbana y procesos de gentrificación. El presente trabajo tiene por objetivo avanzar en el estudio cuantitativo y el análisis espacial de los desplazamientos: ¿Es posible dimensionar los desplazamientos y determinar su espacialidad? ¿Existe una relación entre desplazamientos y la llegada de clases medias y altas a ciertas zonas de la ciudad? Es importante encontrar respuestas, porque si la inversión pública en mejoramiento y renovación urbana, muchas veces concebida para beneficiar las condiciones de vida y oportunidades de los grupos de menor nivel socioeconómico, acaba generando el desplazamiento de estos sectores y beneficiando a otros para quienes no estuvo originalmente destinada, algo debe replantearse (Boyle, 2010).

Para responder estas preguntas desarrollamos una metodología original, que toma como base la información censal disponible en la Argentina. Fundamentalmente se analizan los cambios sociodemográficos ocurridos en cada zona censal de la ciudad en relación con los ocurridos en la ciudad en su conjunto, lo cual nos permite arribar a medidas cuantitativas que pueden interpretarse como indicios de gentrificación y presuntos desplazamientos. La metodología es aplicada al caso de Córdoba en el periodo intercensal comprendido entre 1991 y 2010. Córdoba es la segunda ciudad más grande del país, y respecto de ella existen antecedentes en la literatura que identifican al menos un importante e icónico proceso de gentrificación: el barrio Güemes, ubicado en el borde sur del área central.

Realizamos primero un desarrollo de los conceptos centrales de este trabajo y una revisión de los antecedentes en países anglosajones y nuestra región. Continuamos con una presentación del caso de estudio y un desarrollo de la metodología. Le siguen los resultados y, finalmente, las conclusiones.

\section{Gentrificación y desplazamientos}

Como tantos otros en ciencias sociales, el término gentrificación es polisémico y no hay unanimidad acerca de su significado, como tampoco sobre sus causas y consecuencias (Ellen \& Ding, 2016, p. 3). Es un neologismo proveniente del inglés que puede traducirse al espańol como "aburguesamiento" o "ennoblecimiento" (Carman, 2011). Desde que el término fuera acuñado por Ruth Glass en 1964, la gentrificación ha sido y sigue siendo un tema recurrente de investigación en sociología urbana 
y disciplinas afines, principalmente en países anglosajones y europeos, y más recientemente en América Latina.

Marcuse (1985, p. 199) entiende por gentrificación un proceso donde nuevos residentes mayormente jóvenes, profesionales, con buena educación y altos ingresos, reemplazan a antiguos residentes generalmente de mayor edad, de clase trabajadora, de alguna minoría étnica y con ingresos bajos, en zonas centrales deterioradas y abandonadas. De forma similar, Ellen y Ding (2016, pp. 3-4) la definen como un incremento en el ingreso familiar, nivel educativo y precio de las viviendas en vecindarios centrales previamente habitados por clases bajas. Otra definición, más amplia y flexible, es la que identifica la gentrificación como la producción del espacio por usuarios progresivamente más solventes (Hackworth, 2002). La gentrificación así entendida implica un cambio en el perfil socioeconómico de un barrio de clase baja a partir de la llegada de habitantes de mayor poder adquisitivo, generalmente acompañada de una serie de cambios en el ambiente físico (mejoramiento edilicio, infraestructuras, servicios) y nuevos usos que reemplazan a los previamente existentes.

Sobre las causas de la gentrificación, autores como David Ley (1986, 1987) y Neil Smith $(1982,1987)$ mantuvieron un intenso debate en la década de los ochenta. Ley proponía un modelo explicativo enfocado en la demanda, donde una nueva clase media, vinculada a la economía posindustrial y con nuevas pautas reproductivas y de consumo, expresa una renovada preferencia por la centralidad urbana como alternativa al modo de vida suburbano. En este esquema, el capital simplemente acompaña y se adapta a la demanda, recuperando y poniendo en valor las áreas centrales. Smith, en cambio, argumenta que el motor de la gentrificación es el capital, que se despliega cíclicamente en el espacio buscando donde obtener la mayor rentabilidad. La oleada gentrificadora actual tiene que ver con la magnitud de la brecha de renta, es decir, la diferencia entre la renta actual en las zonas centrales deterioradas, y la renta potencial que se podría obtener en caso de reinvertir en ellas. En este esquema, es la producción la que genera la demanda. Pero no es solo el capital privado el motor de la gentrificación, ya que el Estado también desempeña un rol crucial en alianza con el capital, al proporcionar normativas y planes, junto con orientar espacialmente la inversión pública y el accionar de las instituciones con la finalidad de promover ciertos vecindarios en detrimento de otros, propiciando la relocalización de las personas (Marcuse, 1985; Wacquant, 2008).

Revisiones críticas posteriores a este debate (Hamnett, 2003; Slater, 2006) sostienen que ambas explicaciones sobre la gentrificación son, en última instancia, válidas y complementarias. Tanto la oferta como la demanda son dos términos de una misma ecuación.

La segunda materia de investigación y debate sobre la gentrificación es la referida a sus consecuencias, lo que también ha dado lugar a por lo menos dos posturas principales. De un lado están quienes celebran la gentrificación, argumentando que favorece la mezcla social, étnica y cultural en el espacio; que aumenta la recaudación de impuestos para el estado local; que mejora la calidad de vida, incluso para los habitantes originales de clase baja; y que constituye, en última instancia, el único remedio posible frente al deterioro y abandono de muchos vecindarios (Caulfield, 
1989; Duany, 2001). En la otra vereda se encuentran quienes denuncian que la gentrificación produce los llamados desplazamientos (Elliott-Cooper, Hubbard \& Lees, 2019; Marcuse, 1985; Slater, 2006; Smith, 1982, 1987), también referidos como el "lado oscuro de la gentrificación" (Baeten, Westin, Pull \& Molina, 2017, p. 645). En el mismo sentido, se argumenta que la pretendida "mixidad socioespacial" reivindicada por los celebracionistas no es otra cosa que un eufemismo (Wacquant, 2008, p. 198) y que, de existir, es pasajera en el mejor de los casos. Si se tratara de un interés genuino, las políticas públicas podrían promover la mezcla social posibilitando a los hogares pobres mudarse a los barrios de los ricos (Blomley, 2004, p. 89).

El vínculo entre gentrificación y desplazamientos parece, en teoría, bastante intuitivo desde un punto de vista teórico. La llegada de clases medias y nuevas actividades orientadas al consumo de usuarios de alto poder adquisitivo, junto al despliegue de inversión pública y/o privada en mejoras en el entorno, conducirían a un alza en el costo de vida (precio del suelo, alquileres, impuestos, bienes y servicios de consumo diario), que afecta sustancialmente a los habitantes originarios de clase baja, especialmente inquilinos, quienes se ven inducidos de manera directa o indirecta a retirarse de la zona y buscar vivienda en otro sitio (Slater, 2006; Smith, 1987).

A partir de estas posturas, resulta claro que el concepto de desplazamiento posee una entidad teórica y analítica propia y no puede ser intrínseco a la definición de gentrificación. Tal como afirman Blanco y Apaolaza (2016), el término desplazamiento remite a ideas de "movimiento" o "expulsión", pérdida o carencia de "plaza o lugar". Los autores asocian el desplazamiento a procesos de gentrificación y renovación urbana, dentro de una extensa tipología de otros usos del término en geografía humana (problemáticas y campos muy diversos, que van desde el transporte a las migraciones vinculadas ya sea con desastres naturales o conflictos bélicos).

En su conocido estudio sobre la ciudad de Nueva York, Marcuse (1985) propuso una clasificación donde identifica cuatro tipos de desplazamiento, que pueden ser desencadenados tanto por el abandono como por la gentrificación de un vecindario:

- Desplazamiento directo del último residente. La vivienda queda vacante cuando el último residente se va y no es reemplazado por otro.

- Desplazamiento directo en cadena. Se consideran desplazados los hogares que abandonan el lugar, independientemente de que sean reemplazados por otros. En este caso, la cantidad de hogares desplazados puede exceder la de viviendas vacantes.

- Desplazamiento por exclusión. Cuando una vivienda es abandonada o gentrificada, otro hogar es excluido de la posibilidad de mudarse a ella. Se podría contabilizar la cantidad de hogares que se mudarían a un barrio, pero que no pueden hacerlo.

- Presión de desplazamiento. Contabiliza personas que aún no se retiraron, pero que sienten la presión de hacerlo y probablemente lo harán en algún momento. Es el efecto de cambios dramáticos en el vecindario, ya sea por gentrificación o por abandono. 
Establecer fehacientemente el vínculo entre procesos de gentrificación y desplazamiento no ha resultado sencillo por el momento. Los investigadores enfrentan un problema fundamental, que es la escasez de datos sobre trayectorias residenciales y motivos implicados en el cambio de lugar de residencia de los hogares. Ante la gentrificación, no sabemos quiénes, cuántos, por qué ni adónde se van. Algunos han sugerido incluso que existe una intencionalidad del Estado en no producir estos datos, pues si la información existiera y los masivos desplazamientos pudieran cuantificarse, el Estado estaría obligado a hacer algo al respecto (García Herrera et al., 2007; Janoschka, 2016). En cualquier caso, medir los desplazamientos es como intentar "medir lo invisible" (Atkinson, 2000).

A pesar de las dificultades, en las últimas décadas se han desarrollado distintos trabajos donde se intenta examinar el vínculo entre gentrificación y desplazamientos a partir de información censal y algunas encuestas gubernamentales, principalmente en los Estados Unidos y Reino Unido.

Atkinson (2000) llevó a cabo un estudio en Londres, donde encontró evidencias de que en los barrios gentrificados (definidos a partir del incremento en la presencia de profesionales) hubo, efectivamente, una salida neta (desplazamiento) de población trabajadora y poco calificada. Sin embargo, estudios subsiguientes arribaron a conclusiones opuestas, destacándose el de Freeman y Braconi (2004). Los autores mostraron que, en una serie de barrios gentrificados en Nueva York, la población pobre había sido un $19 \%$ menos proclive a mudarse que la población no pobre. A conclusiones similares arribaron Ellen y O'Regan (2011) usando datos de la AHs (American Housing Survey) correspondientes a todo Estados Unidos; también McKinnish, Walsh y White (2008) hallaron evidencias de que la gentrificación no solo no produce desplazamientos significativos, sino que, además, mejora el nivel de ingresos de los hogares pobres. Finalmente, Newman y Wyly (2006) encontraron que, en la ciudad de Nueva York, la distribución de los desplazados no muestra una correlación espacial con los barrios típicamente considerados gentrificados.

De esta manera, la mayoría de los estudios en el tema han producido evidencias que parecen justificar la postura de los celebracionistas. Si la gentrificación no produce desplazamientos, no existirían más argumentos para oponerse a ella. Respecto a por qué la gentrificación podría no tener un efecto notable sobre los desplazamientos, los estudios aventuran alguna hipótesis. Freeman y Braconi (2004) conjeturan que, frente a la gentrificación, muchos hogares pobres, especialmente propietarios, pueden hacer sacrificios económicos (un ajuste en sus gastos) para poder permanecer en un barrio donde disminuye la criminalidad y pueden beneficiarse de más y mejores servicios.

En América Latina los estudios sobre gentrificación son bastante recientes, y poco se ha hecho hasta ahora para constatar la magnitud, tendencias y patrones espaciales del desplazamiento (Inzulza, 2011). Los trabajos son muy diversos en sus enfoques y metodologías, predominando los de tipo cualitativos, donde se busca analizar y reflexionar sobre la gentrificación en la región.

Carman (2011) estudió la gentrificación en el barrio del Abasto en Buenos Aires, documentando mediante entrevistas y trabajo de campo los desplazamientos -principalmente desalojos ante situaciones de tenencia irregular- de habitantes de 
casas tomadas. También en Buenos Aires, Di Virgilio y Guevara (2014) analizaron el rol del Estado en lo que denominan gentrificación de tipo comercial y turística en los barrios populares -y próximos al centro- de La Boca, San Telmo y Barracas. Janoschka (2016, p. 35) también se inclina por un enfoque cualitativo, proponiendo una serie de dimensiones del desplazamiento (material, política, simbólica y psicológica), a partir de las cuales realiza un análisis comparativo de cinco ciudades latinoamericanas. Entre otros estudios cualitativos se destaca uno reciente de Contreras (2017), que analiza la trayectoria residencial de los "gentrificadores" en el centro de Santiago.

Existen también algunos trabajos que han procurado estudiar la gentrificación y los desplazamientos con algún apoyo en datos estadísticos. Sabatini, Robles y Vásquez (2009, p. 18) analizaron cambios sociodemográficos en la ciudad de Santiago de Chile, concluyendo que la gentrificación podría ser un fenómeno que -a diferencia de los países centrales del norte- no se desarrolla en el centro de la ciudad sino en la periferia, y de allí que no produce desplazamientos. A conclusiones similares arribaron Martí-Costa, Durán y Marulanda (2016) en su estudio sobre la ciudad de Quito, Ecuador. Inzulza (2011) propuso el término "latino gentrificación” para referir al modo particular en que se desarrolla la gentrificación en el área residencial próxima al centro de Santiago, esto es, a través de la edificación en altura (destinada a estratos más solventes), lo cual tampoco estaría generando el desplazamiento de los habitantes originarios. En Ciudad de México, Delgadillo (2016) estudió el impacto de las políticas de renovación urbana y la gentrificación en una serie de zonas seleccionadas a partir de una encuesta de tres mil casos, donde se relevó la percepción subjetiva de los vecinos sobre los cambios producidos en el vecindario (nuevos residentes, nuevos usos, aumento de precios y otros). Dicho trabajo no abordó específicamente el problema de los desplazamientos, aunque las evidencias recolectadas permitirían concluir que las políticas de renovación urbana "han contribuido a la creación de una ciudad cada vez más cara, exclusiva y excluyente” (p. 127). Finalmente, Rodríguez y Cuenya (2018) propusieron un índice estadístico para la identificación de zonas gentrificadas en la ciudad de Rosario, pero donde no se distingue operacionalmente los conceptos de gentrificación y desplazamiento; sin embargo, pudieron mostrar que la gentrificación parece ser un fenómeno bastante más generalizado de lo que se suele pensar, y que no estaría ocurriendo precisamente en las áreas centrales.

En definitiva, la revisión de la literatura sugiere que, particularmente en América Latina, el estudio de los desplazamientos y su vínculo con la gentrificación constituye un campo fértil donde avanzar. Primero, para corroborar si efectivamente existe alguna -o ninguna- relación entre gentrificación y desplazamientos. Y segundo, porque incluso si no existiera dicha asociación, es posible que los desplazamientos estén ocurriendo en otros sitios, de manera menos visible.

\section{Caso de estudio}

Fundada en el año 1573 en la intersección del río Suquía y el arroyo La Cañada, la ciudad de Córdoba es la capital de la provincia homónima. Con casi un millón y medio de habitantes en 2010, Gran Córdoba es, en términos demográficos, la 
segunda aglomeración de Argentina después del Gran Buenos Aires. Actualmente es uno de los principales centros de servicios y comercio del país, aunque con fuerte presencia industrial, oferta turística y un polo universitario de reconocida trayectoria.

Figura I | La ciudad de Córdoba y el sector “G” del barrio Güemes

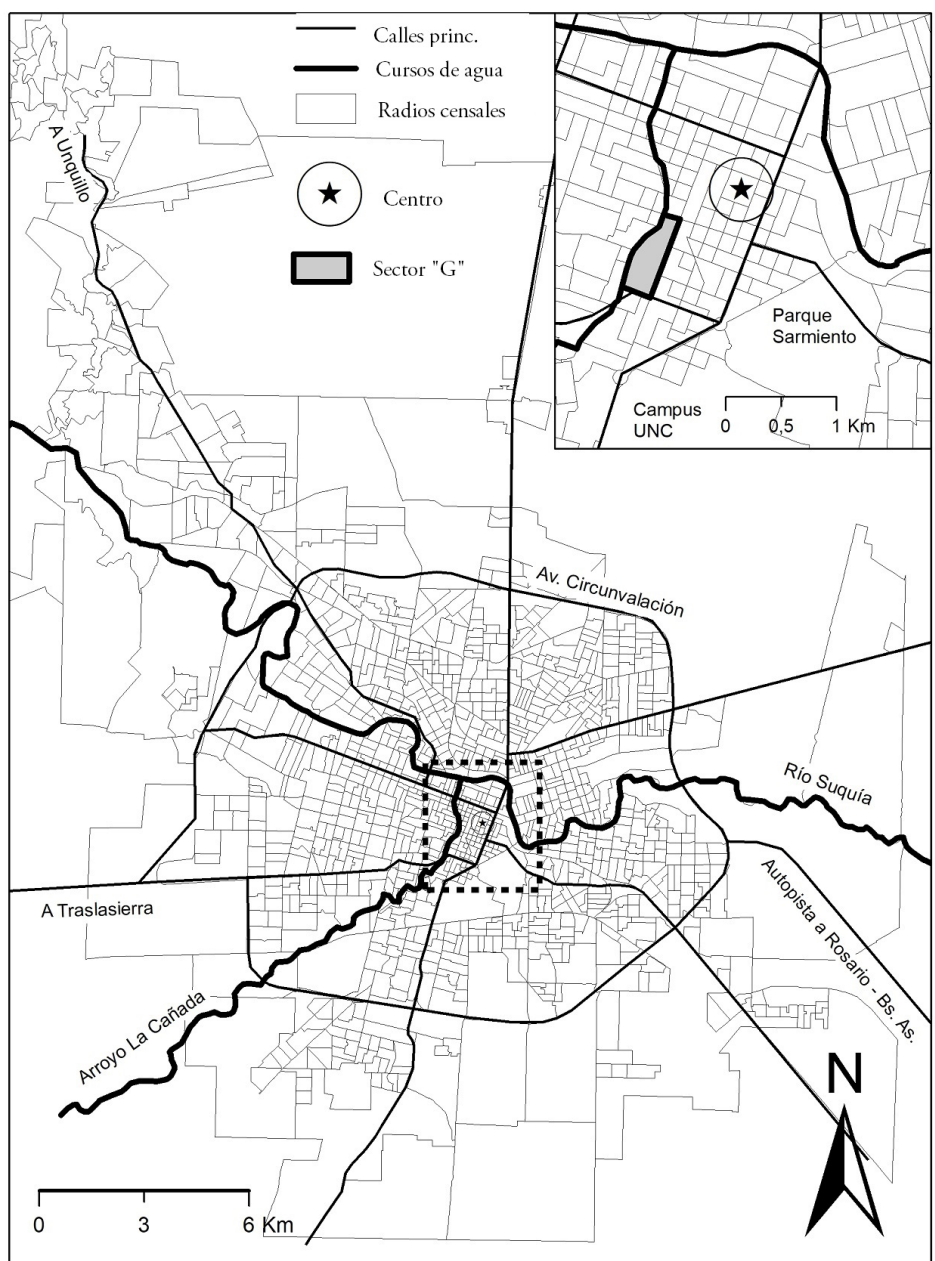

FUENTE: ELABORACIÓN PROPIA

Estudios llevados adelante en la ciudad de Córdoba (Boccolini \& Kirschenmann, 2016; Suyai Pereyra, 2016) coinciden en destacar al menos un sector donde se habría desarrollado un proceso clásico de gentrificación en las últimas décadas: el barrio Güemes, ubicado en el borde sur del área central y muy próximo al campus universitario y el parque Sarmiento. Un barrio "bohemio y rústico, espacio emblemático 
de la feria de 600 artesanos", que viene siendo promocionado por el gobierno local como polo gastronómico y comercial orientado al turismo local e internacional. Desde hace varios años, el proceso de valorización inmobiliaria en el barrio estaría provocando el desplazamiento -directo o indirecto- de la población con menor capacidad económica hacia otras localizaciones (Suyai Pereyra, 2016, p. 2).

La Figura 1 muestra específicamente el pequeño sector (aprox. 5 hectáreas) supuestamente gentrificado del barrio, tal como aparece delimitado en el trabajo de Boccolini y Kirschmann (2016). En adelante, nos referiremos al mismo como sector "G", para diferenciarlo del resto del barrio.

\section{Metodología}

El enfoque metodológico aquí adoptado es estrictamente cuantitativo y, en líneas generales, consiste en la construcción de dos índices, uno de gentrificación y otro de relocalización (y presumible desplazamiento) de hogares de clase baja. Se busca identificar zonas de la ciudad de Córdoba donde se podrían estar produciendo desplazamientos, y determinar si existe alguna relación entre estos y la gentrificación.

Los datos utilizados fueron extraídos de las bases REDATAM del Instituto Nacional de Estadísticas y Censos de Argentina (INDEC), correspondientes a los censos de 1991 y 2010 a nivel de radio censal. ${ }^{1}$ Todos los hogares de Gran Córdoba fueron agrupados en dos categorías de nivel socioeconómico, utilizando como proxy la variable máximo nivel de instrucción completado por el jefe o jefa de hogar: ${ }^{2}$ hogares de nivel socioeconómico bajo (NSB) y hogares de nivel socioeconómico alto (NSA). ${ }^{3} \mathrm{El}$ grupo NSB incluye jefes de hogar sin estudios, hasta nivel primario completo; en este trabajo lo consideramos el grupo potencialmente desplazable. El grupo NSA abarca jefes con educación secundaria completa hasta terciario/universitario completo; operacionalmente lo asumimos como grupo potencialmente gentrificador.

Posteriormente los datos fueron asociados a su respectiva entidad geográfica en el software ArcGIS, utilizando la cartografía censal digital del INDEC en su versión revisada y corregida por Rodríguez (2018). Dado que el tipo de análisis propuesto necesita de datos agrupados en zonas espaciales constantes en forma, tamańo y cantidad, y con el fin de lidiar con el problema de la unidad espacial modificable, o PUEM (Openshaw, 1984), los radios censales subdivididos en 2010 fueron restituidos a los límites originales de 1991.

1 El radio censal es la mínima entidad espacial de agregación de datos disponibles al público en Argentina.

2 El censo en Argentina no recolecta información sobre ingresos. Otras variables (como categoría y calificación ocupacional), que también podrían servir para segmentar socioeconómicamente a la población, no están disponibles a nivel de radio censal para alguno de los dos censos. No utilizamos la variable NBI (necesidades básicas insatisfechas), ya que combina atributos de las personas y las viviendas, es decir, atributos que las personas no necesariamente llevan consigo cuando cambian su lugar de residencia.

3 La variable nivel educativo del jefe de hogar es la más utilizada en el mundo como proxy de nivel socioeconómico, especialmente en el estudio de la gentrificación. El corte es arbitrario, como sería cualquier otro corte, aunque nos asegura una cantidad de casos lo más similar posible en ambos grupos. 
Los radios fueron clasificados de acuerdo con su distancia al centro, definido este como el punto donde se ubica el edificio del antiguo Cabildo, dentro del área conocida como "casco histórico". Se construyeron cinco rangos de distancia con intervalos de 1.500 metros lineales entre el centro de la ciudad y el centroide de cada radio censal. A la primera categoría nos referiremos como "área central"; a los tres rangos siguientes como anillos 1, 2 y 3; y al más lejano, como "periferia”. Esta periferia incluye algunos radios que en 1991 eran rurales, habiéndose integrado a la aglomeración urbana con posterioridad.

La Tabla 1 muestra el crecimiento de la ciudad a lo largo del periodo 19912010 en términos de cantidad de hogares totales y dentro de cada categoría de nivel socioeconómico. Debe notarse que, entre 1991 y 2010, la cantidad de hogares NSB se redujo un 4,4\%, mientras que los hogares NSA registraron un aumento del $104,8 \%$. Estos valores reflejan una tendencia nacional, dando cuenta no solo de jefes de hogar que pudieron haber mejorado su nivel educativo al cabo de las dos décadas sino, principalmente, del recambio generacional implicado en el proceso estructural de movilidad educacional ascendente, donde adultos mayores con menor nivel de estudios fallecen y son "reemplazados" por nuevos hogares jóvenes con mayor nivel educativo. ${ }^{4}$ Los porcentajes $-4,4 \%$ y $+104,8 \%$ correspondientes a la categoría NSB y NSA, respectivamente, constituyen (llevados a proporción) los parámetros de referencia utilizados en el cálculo de los índices de gentrificación y relocalizaciones.

TABLA I | Cambios en la composición socioeconómica de los hogares en la ciudad de Córdoba, 1991-2010

\begin{tabular}{|c|c|c|c|c|c|c|c|}
\hline \multirow{2}{*}{ HOGARES } & \multicolumn{3}{|c|}{ AÑO } & \multicolumn{3}{c|}{ VARIACIÓN } \\
\cline { 2 - 8 } & \multicolumn{2}{|c|}{ I99I } & \multicolumn{2}{c|}{ 20IO } & \multicolumn{3}{c|}{ I99I-20IO } \\
\cline { 2 - 8 } & HOGARES & $\%$ & HOGARES & $\%$ & HOGARES & P.P. & $\begin{array}{c}\text { \% SOBRE } \\
\text { I99I }\end{array}$ \\
\hline NSB & 212.902 & 64,0 & 203.469 & 45,3 & -9.433 & $-18,7$ & $-4,4$ \\
\hline NSA & 119.894 & 36,0 & 245.541 & 54,7 & 125.647 & $+18,7$ & $+104,8$ \\
\hline Total & 332.796 & 100 & 449.010 & 100 & 116.214 & & $+34,9$ \\
\hline
\end{tabular}

FUENTE: ELABORACIÓN PROPIA CON BASE EN DATOS DEL INDEC

Definimos empíricamente la gentrificación como la llegada de nuevos hogares NSA a una determinada zona, lo que supone una intensificación de la competencia por el espacio con los hogares de NSB originarios, más el potencial desplazamiento de estos últimos. En este trabajo asumimos que hubo algún grado de gentrificación allí donde la cantidad de hogares NSA aumentó por encima de la media urbana, independientemente de si hubo o no desplazamientos, de si existe una renovación urbana en términos de inversión pública o privada en el mejoramiento físico y 
ambiental, o de si están presentes otros atributos típicamente asociados a la gentrificación, como la centralidad o el aumento en los precios del suelo (Marcuse, 1985). El índice de gentrificación (IG) se define, entonces, como la variación del grupo NSA en la zona, dividido por la variación del grupo en la ciudad.

$$
I G=\frac{\text { Variación proporcional del grupo NSA en la zona }}{\text { Variación proporcional del grupo NSA en la ciudad }}
$$

El IG puede arrojar cualquier valor menor o mayor que cero, pudiéndose interpretar el mismo según se explica en la Tabla 2.

TABLA 2 Interpretación de los valores del índice de gentrificación

\begin{tabular}{|c|l|}
\hline $\begin{array}{c}\text { VALOR DEL } \\
\text { IG }\end{array}$ & \\
\hline$<0$ & La cantidad de hogares NSA disminuyó (en sentido contrario al conjunto de la ciudad). \\
\hline$=0$ & La cantidad de hogares NSA no registró cambios. \\
\hline $0>\mathrm{y}<1$ & La cantidad de hogares NSA aumentó, pero por debajo de la media urbana. \\
\hline$=1$ & La cantidad de hogares NSA aumentó exactamente igual que la media urbana. \\
\hline$>1$ & La cantidad de hogares NSA aumentó por encima de la media urbana. \\
\hline
\end{tabular}

FUENTE: ELABORACIÓN PROPIA

Tal como lo concebimos aquí, el IG tiene por único fin examinar espacialmente la correlación entre una variable típicamente asociada a la gentrificación (la llegada de clases medias y altas a una zona), con los desplazamientos que presuntamente se derivarían de ella. Dicho esto, el problema con el IG es que, en zonas de nueva urbanización periférica -y eventualmente intersticial- puede alcanzar valores muy altos. Por ello la conveniencia de limitar su aplicación a zonas que al comenzar el periodo ya tuvieran una cantidad considerable de hogares, que aquí establecimos en un mínimo de cien. Adicionalmente, será importante analizar e interpretar sus valores según la distancia al centro.

A fin de identificar y medir potenciales desplazamientos, construimos para cada grupo una medida: el índice de relocalización (IR). Entendemos por relocalizaciones aquellos hogares que presuntamente abandonaron una zona, con independencia de las causas y el lugar de destino. La relocalización incluye tanto los hogares "originarios", como aquellos nuevos hogares jóvenes que, si bien surgieron en la zona durante el periodo, se constituyeron como tales fuera de ella. ${ }^{5}$

La cantidad de relocalizaciones $(\mathrm{R})$ de un grupo puede aproximarse como la diferencia entre la cantidad de hogares observada $(\mathrm{O})$ en 2010 y la cantidad esperada (E) en el mismo año, si el grupo hubiese registrado la misma variación proporcional (V) que en la ciudad durante el periodo:

5 Pensemos, por ejemplo, en una pareja de jóvenes que vivían en la zona con sus respectivas familias al comenzar el periodo y que, al decidir conformar su propia familia, lo hicieron en una nueva vivienda fuera de la zona. 


$$
\begin{gathered}
E=O_{91}+\left(O_{91} \cdot V_{9110}\right) \\
R=E-O_{10}
\end{gathered}
$$

El IR de cada grupo se calcula llevando la cantidad de hogares relocalizados a porcentaje, es decir, respecto a la cantidad esperada (E):

$$
I R=\frac{R}{E} * 100
$$

Si el IR de ambos grupos fuese idéntico, estaríamos en condiciones de asumir dos posibilidades: o bien la "preferencia de permanencia" en la zona es la misma entre los más ricos y los más pobres y, por lo tanto, se han ido quienes se han querido ir, voluntariamente y sin condiciones; o bien la oferta de vivienda en la zona, si bien puede no haber sido suficiente para que todos los hogares permanecieran en ella, no ha beneficiado ni perjudicado a ninguno de los dos grupos en particular. En cualquiera de los casos, la condición socioeconómica no incidió en la probabilidad de los hogares de menores ingresos de permanecer en la zona, por lo que no habrían existido desplazamientos.

Ahora bien, si el IR del grupo NSB resulta ser positivo y mayor al del grupo NSA, esto puede interpretarse como que el grupo NSB tuvo mayores restricciones económicas para permanecer. El saldo positivo entre el IR del grupo NSB y el del grupo NSA puede ser considerado un indicador de la intensidad relativa de los desplazamientos (relocalizaciones económicamente condicionadas) en diferentes zonas de la ciudad. ${ }^{6}$

Los valores obtenidos mediante estas fórmulas se acercan a una medición de los tipos de desplazamiento que Marcuse llama "directo en cadena" y "por exclusión”. Sin embargo, no deben ser interpretados como relocalizaciones ni desplazamientos reales. Imaginamos que podrían variar significativamente si tuviéramos la oportunidad de usar otras variables de segmentación socioeconómica, e incluso si hubiésemos agrupado de otra forma las cuatro categorías de nivel de instrucción de los jefes de hogar. En cualquier caso, confiamos en que, si las relocalizaciones y los desplazamientos existen, estos índices nos darán una buena idea de dónde encontrarlos y de su intensidad relativa respecto a otras zonas.

\section{Resultados}

La cantidad total de hogares aumentó un 34\% en la ciudad de Córdoba a lo largo del periodo 1991-2010, lo cual se tradujo principalmente en una importante expansión urbana periférica, pero también en la densificación de su ejido preexistente e intersticial. Es notable en este sentido la fuerte densificación registrada en el área central, con casi 15 mil nuevos hogares (+47\%). Los anillos 1,2 y 3 también crecieron en cantidad de hogares, pero con una intensidad menor (Tabla 3).

6 Al hacer la resta, los IR negativos deben asumirse como cero. Si no procediéramos de este modo, podrían darse algunas inconsistencias; por ejemplo, afirmar que hubo desplazamientos allí donde ambos IR son negativos. 
La densificación del área central tuvo como protagonistas a los hogares de mayor nivel socioeconómico, existiendo en 2010 un $75 \%$ más de hogares NSA respecto a 1991. Los hogares NSB, en cambio, no solo se redujeron en cantidad (-3.400), sino extraordinariamente por encima de la media urbana ( $47 \%$ frente a $4,4 \%$, respectivamente). ${ }^{7}$ Algo similar sucede en las áreas pericentrales 1 y 2 , con una reducción de hogares NSB por encima de la media urbana, y un importante aumento de hogares NSA, aunque por debajo de la media. Es recién en la periferia donde ambos grupos crecen muy por encima de la media urbana.

TABLA 3 | Cambios en la composición socioeconómica según distancia al centro en la ciudad de Córdoba, 1991-2010

\begin{tabular}{|l|c|c|c|c|c|c|c|c|c|}
\hline \multirow{2}{*}{$\begin{array}{c}\text { ÁREA } \\
\text { URBANA }\end{array}$} & \multicolumn{3}{|c|}{ I99I } & \multicolumn{3}{c|}{ 2OIO } & \multicolumn{2}{c|}{ VARIACIÓN I99I-2OIO } \\
\cline { 2 - 10 } & NSB & NSA & TOTAL & NSB & NSA & TOTAL & NSB & NSA & TOTAL \\
\hline Centro & 7.275 & 23.868 & 31.143 & 3.875 & 41.760 & 45.635 & -3.400 & 17.892 & 14.492 \\
\hline & $23 \%$ & $77 \%$ & $100 \%$ & $8 \%$ & $92 \%$ & $100 \%$ & $-47 \%$ & $75 \%$ & $47 \%$ \\
\hline Anillo 1 & 25.079 & 24.147 & 49.226 & 15.032 & 40.167 & 55.199 & -10.047 & 16.020 & 5.973 \\
\hline & $51 \%$ & $49 \%$ & $100 \%$ & $27 \%$ & $73 \%$ & $100 \%$ & $-40 \%$ & $66 \%$ & $12 \%$ \\
\hline Anillo 2 & 49.249 & 26.209 & 75.458 & 35.192 & 44.150 & 79.342 & -14.057 & 17.941 & 3.884 \\
\hline & $65 \%$ & $35 \%$ & $100 \%$ & $44 \%$ & $56 \%$ & $100 \%$ & $-29 \%$ & $68 \%$ & $5 \%$ \\
\hline Anillo 3 & 47.416 & 17.819 & 65.235 & 44.247 & 38.834 & 83.081 & -3.169 & 21.015 & 17.846 \\
\hline Periferia & $73 \%$ & $27 \%$ & $100 \%$ & $53 \%$ & $47 \%$ & $100 \%$ & $-7 \%$ & $118 \%$ & $27 \%$ \\
\hline & $75 \%$ & $25 \%$ & $100 \%$ & $57 \%$ & $43 \%$ & $100 \%$ & $25 \%$ & $190 \%$ & $66 \%$ \\
\hline TOTAL & 21.2902 & 119.894 & 332.796 & 203.469 & 245.541 & 449.010 & -9.433 & 12.5647 & 116.214 \\
\hline & $100 \%$ & $100 \%$ & $100 \%$ & $100 \%$ & $100 \%$ & $100 \%$ & $4,4 \%$ & $104,8 \%$ & $35 \%$ \\
\hline
\end{tabular}

FUENTE: ELABORACIÓN PROPIA CON BASE EN DATOS DEL INDEC

La Tabla 4 muestra los valores del índice de relocalización (IR) para ambos grupos socioeconómicos según la distancia al centro. Hemos asumido que no existirían desplazamientos (relocalizaciones económicamente condicionadas) si ambos grupos presentaran el mismo IR; es decir, si la probabilidad de habitar en o cerca del centro fuese la misma para todos los hogares con independencia del nivel socioeconómico.

En el área central y anillos 1 y 2, tanto el grupo NSB como el NSA presentan valores positivos en el IR, es decir, existen menos hogares de los que cabría esperar en relación con su variación en el conjunto de la ciudad. Esto sugiere que en ambos grupos hubo un saldo neto de hogares que cambiaron su lugar de residencia alejándose del centro. Existen, sin embargo, diferencias sustantivas de acuerdo al nivel socioeconómico.

En el centro, los hogares NSB presuntamente relocalizados fueron 3.078, lo que arroja el IR más alto de la ciudad (44,3\%). Entre los hogares NSA, los relocalizados

$7 \quad$ Al no disponer de datos de censos anteriores, no podemos inferir que estamos frente a una "reconquista" del área central por los sectores medios y altos. Para testear tal hipótesis, una alternativa viable sería dividir el periodo largo 1991-2010 en dos subperiodos y analizar si existe una tendencia diferencial en ambos. 
fueron cuantitativamente más del doble (7.121), pero significativamente menos en términos relativos, con un IR de 14,6\%. En los anillos 1 y 2, ambos grupos continúan mostrando un IR positivo, manteniéndose por encima el IR del grupo NSB, aunque la diferencia se va haciendo más pequeña.

TABLA 4 Relocalización de hogares NSB y NSA e intensidad del desplazamiento según distancia al centro en la ciudad de Córdoba, 1991-2010

\begin{tabular}{|l|c|c|c|c|c|c|c|c|c|}
\hline \multirow{2}{*}{$\begin{array}{c}\text { ÁREA } \\
\text { URBANA }\end{array}$} & \multicolumn{2}{|c|}{ OBSERVADOS } & \multicolumn{2}{|c|}{ ESPERADOS } & \multicolumn{2}{|c|}{ RELOCALIZADOS } & \multicolumn{2}{|c|}{ IR } & \\
\cline { 2 - 11 } & NSB & NSA & NSB & NSA & NSB & NSA & $\begin{array}{c}\text { NSB } \\
\text { (B) }\end{array}$ & $\begin{array}{c}\text { NSA } \\
\text { (A) }\end{array}$ & $($ B)-(A) \\
\hline Centro & 3.875 & 41.760 & 6.953 & 48.881 & 3.078 & 7.121 & 44,3 & 14,6 & 29,7 \\
\hline Anillo 1 & 15.032 & 40.167 & 23.968 & 49.453 & 8.936 & 9.286 & 37,3 & 18,8 & 18,5 \\
\hline Anillo 2 & 35.192 & 44.150 & 47.067 & 53.676 & 11.875 & 9.526 & 25,2 & 17,7 & 7,5 \\
\hline Anillo 3 & 44.247 & 38.834 & 45.315 & 36.493 & 1.068 & -2.341 & 2,4 & $-6,4$ & $2,4^{*}$ \\
\hline Periferia & 105.123 & 80.630 & 80.166 & 57.038 & -24.957 & -23.592 & $-31,1$ & $-41,4$ & $0 *$ \\
\hline
\end{tabular}

$\left(^{*}\right)$ AL CALCULAR ESTA DIFERENCIA, LOS IR NEGATIVOS SE ASUMEN COMO O

FUENTE: ELABORACIÓN PROPIA CON BASE EN DATOS DEL INDEC

La diferencia en el IR de ambos grupos sugiere una intensidad importante de desplazamientos, particularmente significativa en el área central, donde el IR del grupo NSB es 29,7 puntos mayor que el del grupo NSA. Los desplazamientos se mantienen en los anillos 1 y 2, decreciendo en intensidad hacia la periferia. En el anillo 3, el IR del grupo NSB se vuelve mínimo (2,4\%), mientras que el del grupo nsa ya cambia de signo $(6,4 \%)$, expresando que no solo no hubo relocalizaciones de este grupo, sino que su presencia en el área se incrementó por encima de lo esperado.

En la periferia de la ciudad, el IR alcanza valores negativos muy altos en ambos grupos (24.957 nuevos hogares NSB y 23.592 hogares NSA por encima de los valores esperados). Se evidencia así que fue en la periferia donde se relocalizaron masivamente tanto los hogares de nivel socioeconómico bajo (presuntos desplazados), como aquellos de nivel socioeconómico más alto. La mancha urbana prosigue su expansión, principalmente a partir de nuevas urbanizaciones cerradas, asentamientos precarios y conjuntos de vivienda social, configurando una periferia espacialmente fragmentada y socialmente diferenciada.

La Figura 2 permite ver cómo se distribuyen los niveles de relocalización de hogares NSB, destacándose que fue elevada no solo en proximidad al centro, sino también a lo largo del cono de alta renta (noroeste). La Figura 3, por su parte, muestra cómo se distribuyen espacialmente los valores que resultan de restar el IR NSA al IR NSB, y que aquí hemos considerado una aproximación a la intensidad de los desplazamientos. Se confirma también visualmente que los desplazamientos parecen ser un fenómeno bastante extendido en toda la ciudad.

Finalmente, la Figura 4 muestra dónde se localizan los radios censales con diferente intensidad de gentrificación, definida empíricamente como la llegada significativa de nuevos hogares NSA a una zona determinada. Se puede ver a simple vista una distribución con valores altos en la periferia y tercer anillo - mayormente nuevas 
urbanizaciones-, pero también en algunas zonas puntuales del centro y anillos interiores, correspondientes a la ciudad consolidada.

FIGURA 2 | Índice de relocalización de hogares NSB por radio censal en la ciudad de Córdoba, 1991-2010

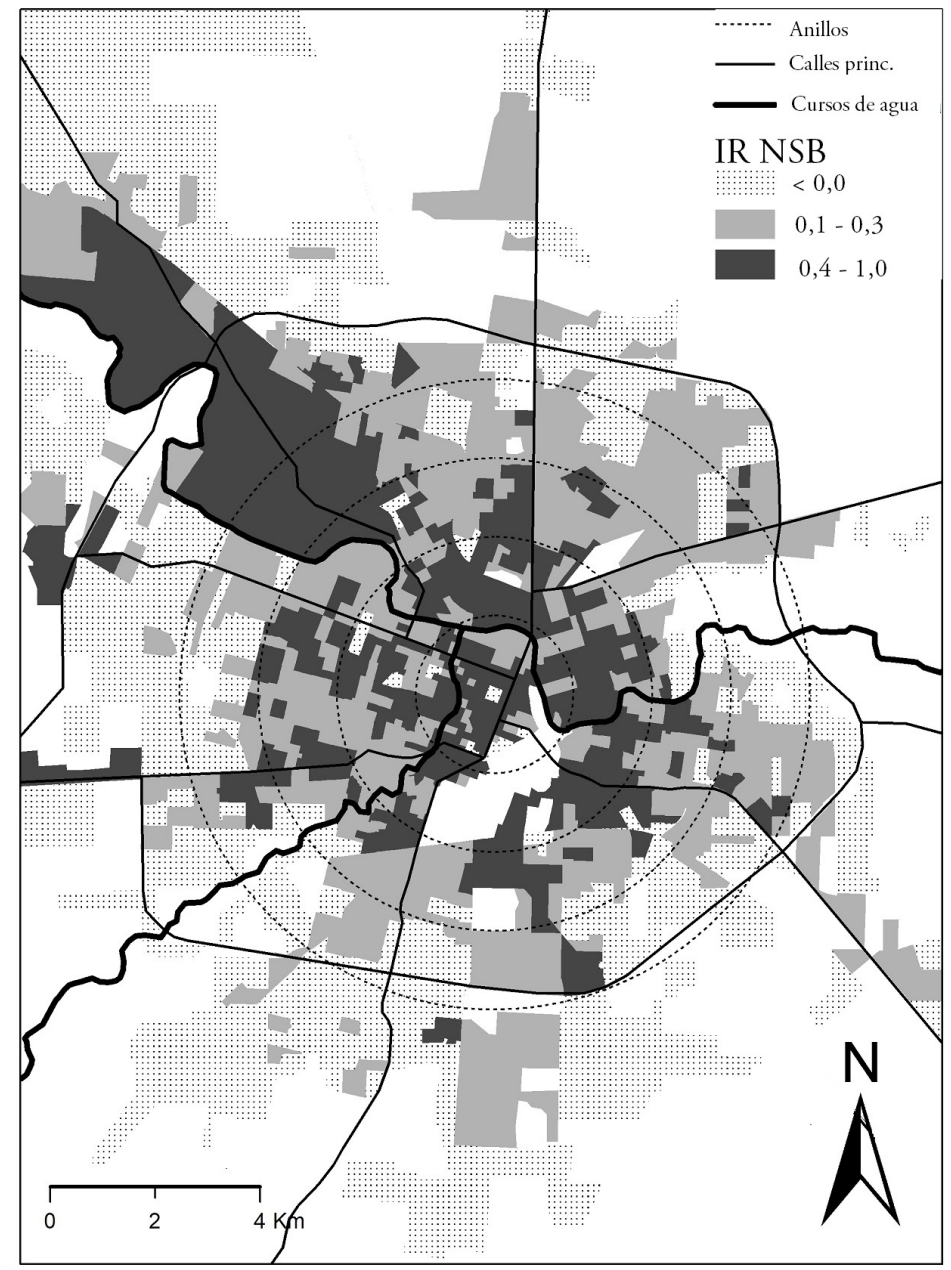

FUENTE: ELABORACIÓN PROPIA CON BASE EN DATOS DEL INDEC 
FIGURA 3 | Intensidad del desplazamiento de hogares NSB por radio censal en la ciudad de Córdoba, 1991-2010

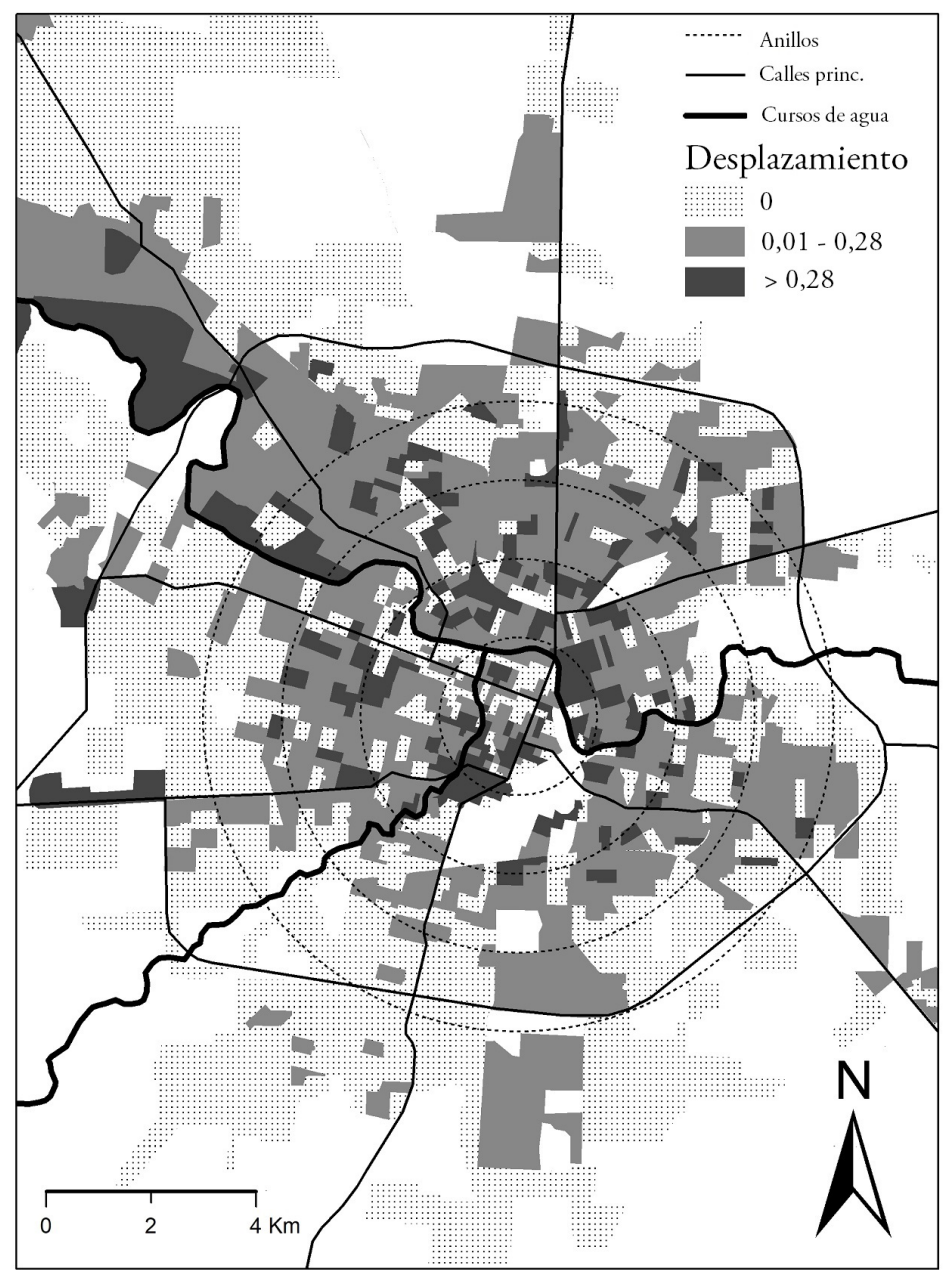

FUENTE: ELABORACIÓN PROPIA CON BASE EN DATOS DEL INDEC

Examinamos ahora los desplazamientos de hogares de menor nivel socioeconómico como posible efecto de la gentrificación. Esta vez, los datos son analizados a nivel de anillos y radios censales, excluyendo aquellos con poca población en alguno de los dos censos (menos de 100 hogares). La hipótesis es que cuanto más aumenta por encima de lo esperado la cantidad de hogares NSA (mayor gentrificación), más alto debería ser el porcentaje de hogares NSB relocalizados (índice de relocalización IR). 
FIGURA 4 | Índice de gentrificación por radio censal en la ciudad de Córdoba, 1991-2010

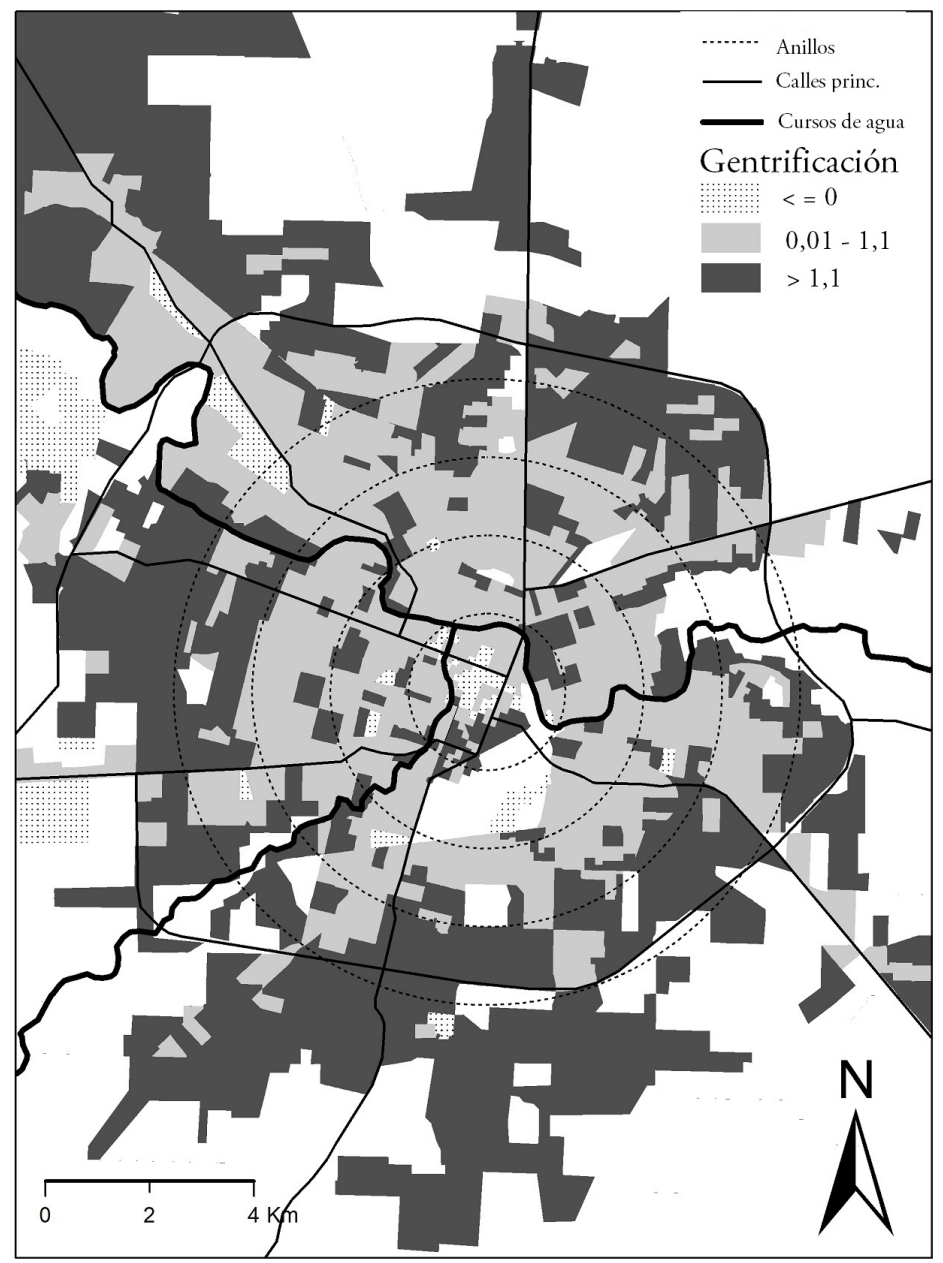

FUENTE: ELABORACIÓN PROPIA CON BASE EN DATOS DEL INDEC

Los datos de la Tabla 5 sugieren que no existe una asociación entre llegada de hogares NSA y relocalización de hogares NSB. Tanto en el área central como en los anillos siguientes, aquellas zonas donde más aumentó la cantidad de hogares NSA (IG >2) tienen en promedio un menor nivel de relocalización del grupo NSB. Y viceversa, es en las zonas donde se redujo la cantidad de hogares NSA donde el IR del grupo NSB alcanza su valor promedio más alto. La misma tendencia se verifica para aquellas zonas donde los hogares NSA aumentaron por debajo de la media urbana, y aquellas con un IG intermedio (entre 1 y 2). De modo general, la gentrificación no parece estar asociada con la relocalización o eventual desplazamiento de hogares de menor nivel socioeconómico. 
TABLA 5 | Gentrificación y desplazamientos según distancia al centro en la ciudad de Córdoba, 1991-2010

\begin{tabular}{|c|c|c|c|c|c|c|}
\hline \multirow[b]{2}{*}{$\begin{array}{c}\text { ÁREA } \\
\text { URBANA }\end{array}$} & \multirow{2}{*}{$\begin{array}{c}\text { RADIOS / } \\
\text { IR NSB } \\
\text { PROMEDIO }\end{array}$} & \multicolumn{4}{|c|}{ GENTRIFICACIÓN } & \multirow{2}{*}{$\begin{array}{c}\text { TOTAL } \\
\text { RADIOS Y } \\
\text { PROMEDIO } \\
\text { IR NSB }\end{array}$} \\
\hline & & $\begin{array}{c}\text { NINGUNA } \\
\text { IG }<0\end{array}$ & $\begin{array}{c}\text { BAJA } \\
\text { IG O-I }\end{array}$ & $\begin{array}{l}\text { MEDIA } \\
\text { IG I-2 }\end{array}$ & $\begin{array}{c}\text { FUERTE } \\
\text { IG }>\mathbf{2}\end{array}$ & \\
\hline \multirow{2}{*}{ Centro } & Radios & 29 & 61 & 26 & 12 & 128 \\
\hline & $\begin{array}{l}\text { IR NSB } \\
\text { promedio }\end{array}$ & 25,4 & 18,3 & $-11,6$ & $-74,5$ & 5,1 \\
\hline \multirow{2}{*}{ Anillo 1} & Radios & 4 & 152 & 33 & 6 & 195 \\
\hline & $\begin{array}{l}\text { IR NSB } \\
\text { promedio }\end{array}$ & 62,8 & 27,8 & $-22,2$ & $-85,4$ & 16,6 \\
\hline \multirow[b]{2}{*}{ Anillo 2} & Radios & 3 & 195 & 61 & 10 & 269 \\
\hline & $\begin{array}{l}\text { IR NSB } \\
\text { promedio }\end{array}$ & 50,1 & 33,4 & $-38,5$ & $-218,3$ & 7,9 \\
\hline \multirow{2}{*}{ Anillo 3} & Radios & 2 & 111 & 64 & 39 & 216 \\
\hline & $\begin{array}{l}\text { IR NSB } \\
\text { promedio }\end{array}$ & 40,3 & 31,2 & $-43,7$ & $-333,2$ & $-56,7$ \\
\hline \multirow{2}{*}{ Periferia } & Radios & 8 & 97 & 104 & 147 & 356 \\
\hline & $\begin{array}{l}\text { IR NSB } \\
\text { promedio }\end{array}$ & 42,9 & 28,6 & $-60,9$ & $-633,6$ & $-270,7$ \\
\hline
\end{tabular}

FUENTE: ELABORACIÓN PROPIA CON BASE EN DATOS DEL INDEC

Resulta de interés, entonces, preguntarnos si acaso existen zonas (en toda la ciudad) que sí presentan al mismo tiempo niveles importantes de gentrificación (IG mayor a 1,1 ) y desplazamientos (IR mayor a 35\%). ${ }^{8}$ En caso de existir, interesa particularmente si estos radios censales se reparten aleatoriamente en la ciudad o presentan alguna tendencia a agruparse en el territorio. Una vez hecho esto, veremos qué ocurrió específicamente en el sector "G" del barrio Güemes.

En efecto, se ha identificado un total de 45 radios censales donde el IG es superior a 1,1 y el IR del grupo NSB es mayor a 35\% (Figura 5). Es importante destacar que estas zonas no parecen distribuirse aleatoriamente, sino que muestran un alto grado de correlación espacial, tendiendo a agruparse entre sí en al menos tres sectores o clústeres.

La Tabla 6 muestra el perfil socioeconómico de estos agrupamientos, incluyendo el sector G del barrio Güemes. El agrupamiento más significativo y compacto está compuesto por 16 radios censales que cubren la casi totalidad del tradicional barrio Nueva Córdoba. Ubicado al sur del área central, es el sector más denso de la ciudad, tanto en habitantes como en edificación en altura. Presenta los niveles más intensos de gentrificación (IG 2,1) y posibles desplazamientos (IR NSB 52,9\%). La particularidad de este sector es que no era precisamente "obrero" o "popular" a comienzos del periodo, sino más bien de clases medias. Solo el 21\% de los hogares correspondía a la categoría NSB en 1991, reduciéndose este porcentaje al 4\% dos décadas después. Estos datos sugieren hablar de un proceso de "supergentrificación" (Butler \& Lees, 2006), donde las elites reemplazan a las clases medias, antes que estas a las clases bajas.

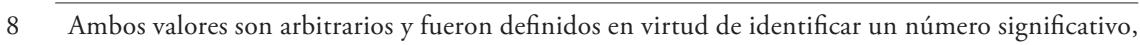
pero no excesivo de radios censales. 
FIGURA 5 | Sectores con niveles significativos de gentrificación y desplazamiento en la ciudad de Córdoba, 1991-2010

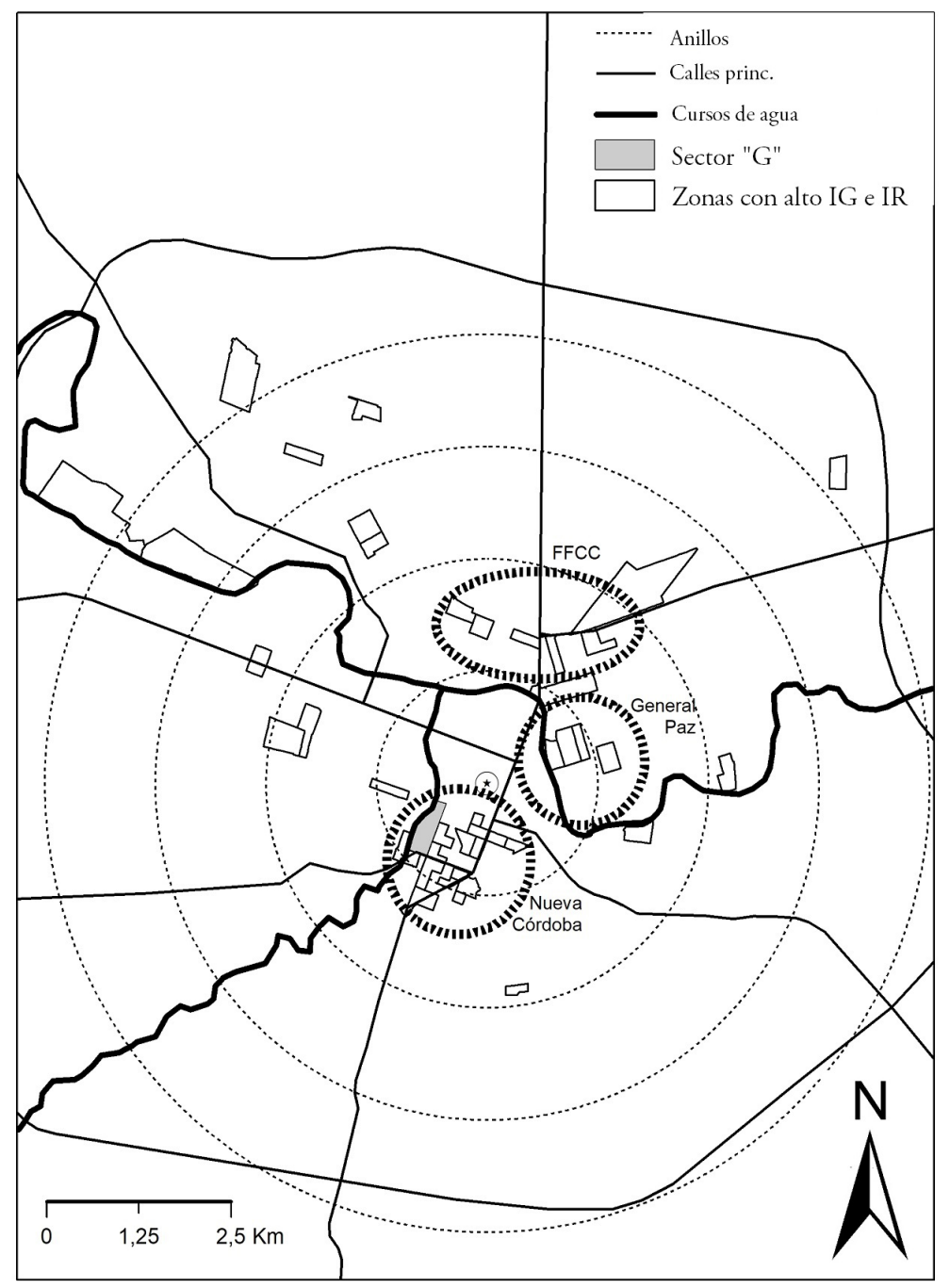

FUENTE: ELABORACIÓN PROPIA CON BASE EN DATOS DEL INDEC 
TABLA 6 | Sectores con niveles significativos de gentrificación y desplazamiento en la ciudad de Córdoba, y comparación con el sector "G" del barrio Güemes, 1991-2010

\begin{tabular}{|c|c|c|c|c|c|c|c|c|c|c|c|}
\hline \multirow{2}{*}{ SECTOR } & \multirow{2}{*}{ RADIOS } & \multicolumn{2}{|c|}{ I99I } & \multicolumn{2}{|c|}{ ESPERADOS } & \multicolumn{2}{|c|}{2010} & \multicolumn{2}{|c|}{ RELOCALIZADOS } & \multirow{2}{*}{ IG } & \multirow{2}{*}{ IR } \\
\hline & & NSB & NSA & NSB & NSA & NSB & NSA & NSB & NSA & & \\
\hline \multirow{2}{*}{$\begin{array}{l}\text { Nueva } \\
\text { Córdoba }\end{array}$} & 16 & 884 & 3.245 & 845 & 6.646 & 398 & 10.109 & 447 & -3463 & 2,1 & 52,9 \\
\hline & & $21 \%$ & $79 \%$ & & & $4 \%$ & $96 \%$ & & & & \\
\hline \multirow{2}{*}{$\begin{array}{l}\text { General } \\
\text { Paz }\end{array}$} & 4 & 374 & 467 & 357 & 956 & 184 & 1.278 & 173 & -322 & 1,7 & 48,5 \\
\hline & & $44 \%$ & $56 \%$ & & & $13 \%$ & $87 \%$ & & & & \\
\hline \multirow{2}{*}{ FFCC } & 7 & 983 & 584 & 939 & 1.196 & 497 & 1.467 & 442 & -271 & 1,5 & 47,1 \\
\hline & & $63 \%$ & $37 \%$ & & & $25 \%$ & $75 \%$ & & & & \\
\hline \multirow{2}{*}{$\begin{array}{l}\text { Otros } \\
\text { dispersos }\end{array}$} & 18 & 3.221 & 2.360 & 3.078 & 4.833 & 1.764 & 6.280 & 1.314 & -1447 & 1,7 & 42,7 \\
\hline & & $58 \%$ & $42 \%$ & & & $22 \%$ & $78 \%$ & & & & \\
\hline \multirow{2}{*}{$\begin{array}{l}\text { “G” } \\
\text { Güemes }\end{array}$} & 4 & 282 & 801 & 270 & 1.640 & 131 & 1.554 & 139 & 86 & 0,9 & 51,4 \\
\hline & & $26 \%$ & $74 \%$ & & & $8 \%$ & $92 \%$ & & & & \\
\hline
\end{tabular}

FUENTE: ELABORACIÓN PROPIA CON BASE EN DATOS DEL INDEC

Un segundo sector lo integran cuatro radios censales en el barrio General Paz, al este, entre el área central y el primer anillo, justo al sur del parque homónimo y de varios desarrollos comerciales de gran envergadura que surgieron en los últimos años. En esta área tampoco predominaba un perfil socioeconómico bajo en 1991, aunque se puede decir que, comparado con Nueva Córdoba, era algo más popular. También experimentó un alto grado de gentrificación (IG 1,7) y presuntos desplazamientos (IR 48,5\%).

En tercer lugar, podemos mencionar un conjunto de siete zonas bastante próximas entre sí, que atraviesan varios barrios dentro del primer anillo al norte del área central (barrios Alta Córdoba, Bustos, Pueyrredón y Talleres). Su característica sobresaliente es que, salvo uno, todos limitan con el ferrocarril y otros importantes equipamientos ferroviarios (Talleres de la línea Ferrocarril General Manuel Belgrano [FCGMB] y Estación Alta Córdoba). De allí que, para fines prácticos, los hemos agrupado bajo el nombre de sector FFCC. A diferencia de los dos agrupamientos anteriores, esta área sí se caracteriza por haber concentrado población predominantemente de clase baja en 1991, desarrollando desde entonces un proceso relativamente fuerte de gentrificación (IG 1,5) con desplazamientos (IR 47,1\%).

En cuanto a su composición socioeconómica, el sector "G" del barrio Güemes presentaba un panorama bastante similar al sector de Nueva Córdoba (con el cual limita al este) tanto en 1991 como en 2010, y también un alto índice de posibles desplazamientos (IR 51,4\%). Nótese que, sin embargo, el IG es de apenas 0,9 en este sector, escasamente por debajo de la media urbana, pero muy por debajo de los sectores previos. En el caso de este sector del barrio Güemes, los desplazamientos no aparecen, entonces, relacionados con la llegada de grupos de mayor nivel socioeconómico. Se podría conjeturar que ha sido otro tipo de gentrificación, más bien comercial y turística (que modificó el perfil del barrio en las últimas décadas, 
orientado a consumidores de mayor poder adquisitivo), lo que ha inducido a los desplazamientos, producto de un posible aumento en el precio del suelo. Otra posibilidad es que las dos décadas analizadas nos estén mostrando apenas un fragmento de un proceso de más largo plazo, donde la llegada masiva de clases medias y altas al barrio se produjo con anterioridad a la década de los noventa, y posteriormente se tradujo en masivos desplazamientos. Lamentablemente no estamos en condiciones de examinar esta hipótesis, dado que no existen los datos necesarios.

\section{Conclusiones}

Hemos procurado partir de una acepción amplia, flexible y operativa del concepto de gentrificación, donde no se asumen los desplazamientos como atributo necesario de la gentrificación, sino como un posible efecto que es preciso determinar. La pregunta clave de la que hemos partido es dónde existen desplazamientos de clases bajas, y hasta qué punto esos desplazamientos pueden estar siendo inducidos por la llegada de clases medias o altas a un barrio (un aspecto clave de la gentrificación). En la literatura sobre el tema no se han encontrado evidencias concluyentes al respecto, y de allí la novedad de este trabajo, particularmente en la Argentina.

Un importante hallazgo es que los desplazamientos no solo existen, sino que parecen estar sucediendo en buena parte de la ciudad. La mayor intensidad se observa en el área central, y se va reduciendo a medida que aumenta la distancia al centro. Es recién en la periferia donde se incrementa la cantidad absoluta de hogares de menor nivel socioeconómico, lo cual sugiere que es precisamente esta periferia el lugar de destino de los hogares presuntamente desplazados.

Respecto al vínculo entre gentrificación y desplazamientos, las evidencias encontradas resultan ambiguas. A nivel agregado la hipótesis no parece verificarse, existiendo, al contrario, una tendencia según la cual las zonas de la ciudad que aumentaron su cantidad de hogares de mayor nivel socioeconómico por encima de la media urbana son, en promedio, aquellas con menor nivel de desplazamiento de hogares de clase baja. Y viceversa, allí donde hubo un retiro neto de hogares más solventes, fue aún más intensa la salida de grupos más vulnerables. Este hallazgo es sugestivo, aunque no es novedoso, ya que va en sintonía con las conclusiones a las que arribaron otros estudios realizados a partir de distintas metodologías, también cuantitativas, en países anglosajones.

Específicamente, el sector que aquí hemos denominado "G" del barrio Güemes -al que, recordemos, se suele identificar como el caso más típico de gentrificación en la ciudad de Córdoba- se ajusta al panorama anterior: un nivel alto de desplazamientos, pero sin indicios estadísticos de que los mismos hayan sido inducidos por la llegada de nuevos habitantes de clase media o alta. Los datos del próximo Censo 2020, ${ }^{9}$ una vez disponibles, podrán servir de insumo para confirmar o eventualmente corregir estas conclusiones.

No obstante, hemos podido identificar un conjunto importante de zonas donde sí se observan simultáneamente niveles significativos de gentrificación y 
desplazamiento. Estas zonas tienden a encontrarse espacialmente agrupadas en tres sectores, que no representaban a priori casos emblemáticos de gentrificación, de acuerdo con la literatura. Un primer sector al sur del área central (casi todo el barrio Nueva Córdoba), que ya era de clase media-alta a comienzos del periodo; un segundo sector, más pequeño, al este del área central (barrio General Paz), con perfil socioeconómico medio; y, por último, un tercer sector de características más populares u obreras, en el segundo anillo al norte del área central (barrios Alta Córdoba, Talleres, Bustos y Pueyrredón), estructurado en torno a importantes infraestructuras ferroviarias.

Futuros estudios podrán indagar más en profundidad por qué la llegada de hogares de mayor nivel socioeconómico en algunas zonas produce desplazamientos mientras que en otras no ocurre, lo cual puede ser fundamental para el diseńo de políticas focalizadas en diferentes tipos de procesos y territorios. Por lo pronto, estas evidencias invitan a los investigadores a ampliar la mirada sobre la escala de la gentrificación y sus efectos, no limitándose a aquellos sectores de la ciudad donde ya se ha definido de antemano que hubo gentrificación. Los resultados sugieren que el problema puede ser, en realidad, mucho más extendido y complejo respecto a lo que comúnmente se asume desde los enfoques críticos de la renovación urbana y la gentrificación.

Cabe aclarar que en este trabajo no hemos abordado — más allá de alguna referencia - el efecto de la renovación urbana (que incluye distintas formas de intervención en el territorio) sobre los desplazamientos, habiéndonos limitado estrictamente al análisis de la relación entre llegada de clases altas y desplazamiento de clases bajas. Por lo tanto, nada podemos afirmar sobre si la renovación urbana es causal o no de desplazamientos. Tal análisis ayudaría a responder la pregunta de a quiénes beneficia o perjudica la inversión del Estado, y podría realizarse delimitando estas zonas de renovación y comparando sus cambios con el resto de la ciudad.

Finalmente, confiamos en que el método propuesto para identificar, dimensionar y espacializar los desplazamientos admite ser perfeccionado y adaptado a otros contextos y países que difieren en la cantidad, tipo y calidad de información disponible. Correctamente complementada con estudios cualitativos y teóricos, y sin renunciar a la necesidad de que el Estado produzca datos sobre trayectorias residenciales, la herramienta es potencialmente útil para evaluar el impacto incluyente o excluyente de las políticas públicas urbanas en el territorio.

\section{Referencias bibliográficas}

Atkinson, R. (2000). Measuring gentrification and displacement in Greater London. Urban Studies, 37(1), 149-165. https://doi.org/10.1080\%2F0042098002339

Baeten, G., Westin, S., Pull, E. \& Molina, I. (2017). Pressure and violence: Housing renovation and displacement in Sweden. Environment and Planning A, 49(3), 631-651. https:// doi.org/10.1177\%2F0308518X16676271 
Blanco, J. \& Apaolaza, R. (2016). Políticas y geografías del desplazamiento. Contextos y usos conceptuales para el debate sobre gentrificación. INVI, 31(88), 73-98. http:// revistainvi.uchile.cl/index.php/INVI/article/view/1085

Blomley, N. (2004). Unsettling the city: urban land and the politics of property. Nueva York: Routledge.

Boccolini, S. M. \& Kirschenmann, C. S. (2016). Visibilizando procesos de gentrificación en Córdoba, Argentina. El caso del barrio Güemes. Trabajo presentado al 1er Congreso Internacional "Contested Cities", Madrid, 4-7 de julio 2016. https://bit.ly/3gtBHpJ

Borsdorf, A. (2003). Cómo modelar el desarrollo y la dinámica de la ciudad latinoamericana. EURE, 29(86), 37-49. http://dx.doi.org/10.4067/S0250-71612003008600002

Boyle, I. (2010). Measuring gentrification in the interstate corridor urban renewal area. Institute of Portland Metropolitan Studies. https://www.pdx.edu/ims/sites/www.pdx.edu.ims/ files/RussillBoylegentrification.pdf

Butler, T. \& Lees, L. (2006). Super-gentrification in Barnsbury, London: Globalization and gentrifying global elites at the neighbourhood level. Transactions of the Institute of British Geographers, 31(4), 467-487. https://doi.org/10.1111/j.1475-5661.2006.00220.x

Carman, M. (2011). El proceso de ennoblecimiento y la salida negociada de los innobles en Buenos Aires. Cadernos Metrópole, 13(25), 257. http://revistas.pucsp.br/metropole/ article/view/5990

Caulfield, J. (1989). 'Gentrification' and desire. Canadian Review of Sociology and Anthropology, 26(4), 617-632. https://doi.org/10.1111/j.1755-618X.1989.tb00437.x

Contreras, Y. (2017). De los "gentries" a los precarios urbanos. Los nuevos residentes del centro del Santiago. EURE, 43(129), 115-141. http://dx.doi.org/10.4067/S025071612017000200006

Delgadillo, V. (2016). Ciudad de México, quince años de desarrollo urbano intensivo: la gentrificación percibida. INVI, 31(88), 101-129. http://revistainvi.uchile.cl/index. $\mathrm{php} / \mathrm{INVI} /$ article/view/1088

Di Virgilio, M. \& Guevara, T. (2014). Gentrificación liderada por el Estado y empresarialismo urbano en la Ciudad Autónoma de Buenos Aires. Revista Estudios Sociales Contemporáneos, (11), 12-23. https://bdigital.uncu.edu.ar/objetos_digitales/6820/02divirgilio-esc11.pdf

Duany, A. (2001). Three cheers for gentrification. American Enterprise Magazine, (15), 36-39. https://bit.ly/3ipDHBj

Ellen, I. G. \& Ding, L. (2016). Advancing our understanding of gentrification. Cityscape: A Journal of Policy Development and Research, 18(3), 3-8. https://www.huduser.gov/ portal/periodicals/cityscpe/vol18num3/guest.pdf

Ellen, I. G. \& O’Regan, K. M. (2011). How low income neighborhoods change: Entry, exit, and enhancement. Regional Science and Urban Economics, 41(2), 89-97. https://doi. org/10.1016/j.regsciurbeco.2010.12.005

Elliott-Cooper, A., Hubbard, P. \& Lees, L. (2019). Moving beyond Marcuse: Gentrification, displacement and the violence of un-homing. Progress in Human Geography, 44(3), 492-509. https://doi.org/10.1177\%2F0309132519830511

Freeman, L. \& Braconi, F. (2004). Gentrification and displacement: New York City in the 1990s. Journal of the American Planning Association, 70(1), 39-52. http://dx.doi. org/10.1080/01944360408976337 
García Herrera, L. M., Smith, N. \& Mejías Vera, M. A. (2007). Gentrification, displacement, and tourism in Santa Cruz de Tenerife. Urban Geography, 28(3), 276-298. https://doi. org/10.2747/0272-3638.28.3.276

Hackworth, J. (2002). Postrecession gentrification in New York City. Urban Affairs Review, 37(6), 815-843. https://doi.org/10.1177\%2F107874037006003

Hamnett, C. (2003). Gentrification and the middle-class remaking of inner London, 1961-2001. Urban Studies, 40(12), 2401-2426. https://doi.org/10.1080\% 2F0042098032000136138

Inzulza, J. (2011). 'Latino Gentrification'? Focusing on physical and socioeconomic patterns of change in Latin American inner cities. Urban Studies, 49(10), 2085-2107. https://doi. org/10.1177/0042098011423425

Janoschka, M. (2016). Gentrificación, desplazamiento, desposesión: procesos urbanos claves en América Latina. INVI, 31(88), 27-71. http://revistainvi.uchile.cl/index.php/INVI/ article/view/1087

Ley, D. (1986). Alternative explanations for inner-city gentrification: A Canadian assessment. Annals of the Association of American Geographers, 76(4), 521-535. https://doi. org/10.1111/j.1467-8306.1986.tb00134.x

Ley, D. (1987). Reply: The rent gap revisited. Annals of the Association of American Geographers, 77(3), 465-468. https://doi.org/10.1111/j.1467-8306.1987.tb00172.x

Marcuse, P. (1985). Gentrification, abandonment, and displacement: Connections, causes, and policy responses in New York City. Urban Law Annual, 28(1/4), 195-240. https:// openscholarship.wustl.edu/law_urbanlaw/vol28/iss1/4

Martí-Costa, M., Durán, G. \& Marulanda, A. (2016). Entre la movilidad social y el desplazamiento. Una aproximación cuantitativa a la gentrificación en Quito. INVI, 31(88), 131-160. http://revistainvi.uchile.cl/index.php/INVI/article/view/1092

McKinnish, T., Walsh, R. \& White, K. (2008). Who gentrifies low-income neighborhoods? NBER Working Paper Series (14036). https://doi.org/10.3386/w14036

Naciones Unidas (onu). (2016). Nueva agenda urbana. Documento final de la Conferencia Hábitat III [Conferencia de las Naciones Unidas sobre la Vivienda y el Desarrollo Urbano Sustentable], Quito, 17-20 de octubre 2016. http://habitat3.org/wp-content/ uploads/NUA-Spanish.pdf

Newman, K. \& Wyly, E. K. (2006). The right to stay put, revisited: Gentrification and resistance to displacement in New York City. Urban Studies, 43(1), 23-57. https://doi. org/10.1080\%2F00420980500388710

Openshaw, S. (1984). The modifiable areal unit problem. Norwich: Geo Books.

Rodríguez, G. M. (2018). Cartografía censal del INDEC revisada y corregida, ańos 1991, 2001 y 2010. http://www.ceur-conicet.gov.ar/transferencia_y_vinculacion.php

Rodríguez, G. M. \& Cuenya, B. (2018). Derivaciones del gran proyecto Puerto Norte en el barrio Refinería de la ciudad de Rosario, Argentina, 2001-2010. Papeles de Población, CIEAP/UAEM, 24(96), 255-286. http://dx.doi.org/10.22185/24487147.2018.96.21

Sabatini, F., Cáceres, G. \& Cerdá, J. (2001). Segregación residencial en las principales ciudades chilenas: Tendencias de las tres últimas décadas y posibles cursos de acción. EURE, 27(82), 21-42. http://dx.doi.org/10.4067/S0250-71612001008200002 
Sabatini, F., Robles, M. S. \& Vásquez, H. (2009). Gentrificación sin expulsión, o la ciudad latinoamericana en una encrucijada histórica. Revista 180, (24), 18-25. http://dx.doi. org/10.32995/rev180.Num-24.(2009).art-266

Slater, T. (2006). The eviction of critical perspectives from gentrification research. International Journal of Urban and Regional Research, 30(4), 737-757. http://doi.org/10.1111/ j.1468-2427.2006.00689.x

Smith, N. (1982). Gentrification and uneven development. Economic Geography, 58(2), 139155. http://doi.org/10.2307/143793

Smith, N. (1987). Gentrification and the rent gap. Annals of the Association of American Geographers, 77(3), 462-465. https://doi.org/10.1111/j.1467-8306.1987.tb00171.x

Suyai Pereyra, A. (2016). Gentrificación, planificación urbana y disputas urbanas en los barrios de Güemes y Alberdi. Trabajo presentado al 1er Congreso Internacional "Contested Cities", Madrid, 4-7 de julio 2016. https://bit.ly/2NNCvK1

Wacquant, L. (2008). Relocating gentrification: The working class, science and the State in recent urban research. International Journal of Urban and Regional Research, 32(1), 198-205. https://doi.org/10.1111/j.1468-2427.2008.00774.x 